\title{
Antibiotic Therapy is Associated with Worse Outcome in Patients with Hepatocellular Carcinoma Treated with Sorafenib
}

\author{
Katharina Pomej (D) $1,2, *$ \\ Lorenz Balcar (iD) ${ }^{1-3, *}$ \\ Bernhard Scheiner ${ }^{1-4}$ \\ Georg Semmler ${ }^{1,3}$ \\ Tobias Meischl (D) 1,2 \\ Mattias Mandorfer ${ }^{1,3,4}$ \\ Thomas Reiberger ${ }^{1,3-5}$ \\ Christian Müller ${ }^{1,2}$ \\ Michael Trauner ${ }^{1,4}$ \\ Matthias Pinter ${ }^{1,2,4}$ \\ 'Division of Gastroenterology and \\ Hepatology, Department of Internal \\ Medicine III, Medical University of Vienna, \\ Vienna, Austria; ${ }^{2}$ Liver Cancer (HCC) \\ Study Group Vienna, Medical University \\ of Vienna, Vienna, Austria; ${ }^{3}$ Vienna \\ Hepatic Hemodynamic Laboratory, \\ Medical University of Vienna, Vienna, \\ Austria; ${ }^{4}$ Rare Liver Disease (RALID) \\ Centre of the ERN RARE-LIVER, Medical \\ University of Vienna, Vienna, Austria; \\ ${ }^{5}$ Christian Doppler Laboratory for Portal \\ Hypertension and Liver Fibrosis, Medical \\ University of Vienna, Vienna, Austria
}

*These authors contributed equally to this work
Background: Antibiotic treatment (ABT) affects the outcome of cancer patients treated with immune checkpoint inhibitors (ICIs) and chemotherapy, possibly by altering the gut microbiome. We investigated the impact of ABT on overall survival (OS) and progressionfree survival (PFS) in patients with advanced HCC treated with sorafenib.

Methods: HCC patients treated with sorafenib between 05/2006 and 03/2020 at the Medical University of Vienna were retrospectively analyzed. ABT was defined as antibiotic use within 30 days prior to or after sorafenib initiation.

Results: Of 206 patients, the majority was male ( $n=171,83 \%$ ) with a mean age of $66 \pm 9.6$ years. Half of patients ( $\mathrm{n}=94,46 \%)$ had impaired liver function (Child-Pugh stage B). Median time of follow-up was 10.8 (95\% CI: 9.2-12.3) months. ABT was administered in $23(11 \%)$ patients due to different types of proven or clinically suspected bacterial infections $(n=17,74 \%)$ and hepatic encephalopathy $(n=6,26 \%)$. The median duration of ABT was 14 (IQR: $12-30)$ days. Penicillin $(n=13,57 \%)$, followed by rifaximin $(n=6,26 \%)$, fluoroquinolones $(n=3,13 \%)$, and cephalosporins $(n=1,4 \%)$, was administered in the ABT group. The ABT group had a significantly shorter median OS (4.7 (95\% CI: 3.2-6.1) months vs 11.4 (95\% CI: 9.9-12.9) months, $\mathrm{p}=0.012$ ), which was confirmed in multivariable analysis (HR: 1.91 (95\% CI: 1.1-3.2), $\mathrm{p}=0.014)$. Similarly, PFS trended to be shorter in the ABT group (3.5 (95\% CI: 1.6-5.4) months vs 4.8 (95\% CI: 3.9-5.7) months, $\mathrm{p}=0.099$ ). None of the 10 patients with complete or partial response was found in the ABT group.

Conclusion: ABT was independently associated with worse outcomes in sorafenib-treated HCC patients. Prospective studies are needed to elucidate the underlying mechanism.

Keywords: antibiotics, hepatocellular carcinoma, sorafenib, targeted therapy

\section{Introduction}

Hepatocellular carcinoma (HCC) accounts for the majority (70-90\%) of primary liver cancers and represents the second and sixth most common cause of cancerrelated death in men and women, respectively. ${ }^{1,2}$ HCC develops predominantly in patients with underlying cirrhosis ${ }^{3,4}$ and is often detected in advanced stages where systemic therapy is the only treatment option. 5,6

For over a decade, the multi-tyrosine kinase inhibitor (TKI) sorafenib remained the standard of care in patients with advanced HCC. ${ }^{5}$ Recently, the combination of atezolizumab plus bevacizumab showed superiority over sorafenib regarding both primary endpoints overall survival (OS) and progression-free survival (PFS), ${ }^{7}$ and consequently became the new reference standard in first-line systemic treatment. ${ }^{8,9}$
Correspondence: Matthias Pinter Division of Gastroenterology and Hepatology, Department of Internal Medicine III, Medical University of Vienna, Währinger Gürtel 18-20, Vienna, 1090, Austria

Tel +43 I 4040047440

Fax +43 I 4040047350

Email matthias.pinter@meduniwien.ac.at 
Nevertheless, sorafenib will continue to play a key role in the treatment algorithm of advanced HCC given that other effective systemic therapies (eg, regorafenib, cabozantinib, ramucirumab) have only been approved for sorafenibexperienced individuals. ${ }^{5,10-12}$

Patients with cancer are susceptible to bacterial infections due to the immunosuppressive milieu caused by the malignancy itself and due to treatment-related immunosuppression. ${ }^{13}$ Thus, cancer patients often receive antibiotic treatment (ABT), which modulates the gut microbiome. Gut microbiota regulate tumor-promoting and tumor-suppressing pathways in patients with $\mathrm{HCC},{ }^{14,15}$ and may influence response to ICIs in different types of cancers. ${ }^{16-19}$ Mice with a favourable composition of the commensal microbiome experienced a greater therapeutic activity from ICI therapy. ${ }^{19,20}$ While modulation of the gut microbiome by fecal microbiota transplant promoted response to ICIs in immunotherapy-refractory melanoma patients, ${ }^{21,22}$ ABT was associated with shorter survival in patients with different cancer types treated with ICIs $^{16,23}$ and TKIs. ${ }^{17,24}$ Patients with advanced chronic liver disease (ACLD) commonly suffer from intestinal dysbiosis and bacterial translocation, which may promote immune dysfunction via the gut-liver axis. ${ }^{25,26}$ Accordingly, the modulation of the gut microbiome could have even more profound effects in patients with HCC than in other tumors. ${ }^{14,27}$

The impact of ABT on the outcome of cancer patients treated with tyrosine kinase inhibitors (TKIs) is unclear. Thus, we investigated the association between early ABT and survival in patients with advanced HCC treated with sorafenib.

\section{Materials and Methods Study Design}

We retrospectively included patients treated with sorafenib for advanced HCC between 05/2006 and 03/2020 at the Division of Gastroenterology and Hepatology, Vienna General Hospital/Medical University of Vienna. Diagnosis of HCC was established by histology or dynamic imaging (computed tomography $[\mathrm{CT}]$ /magnetic resonance imaging [MRI] scans) according to the European Association for the Study of the Liver (EASL) guidelines. ${ }^{2}$ Data analysis was performed in accordance with the Helsinki Declaration and approved by the local ethics committee of the Medical University of Vienna (\#1759/2015). A written informed consent was waived by the local ethics committee due to the retrospective design of this study. All individually identifiable patient data were assessed in a confidential manner that prevented unauthorized use and disclosure to any third parties/persons.

\section{Patients and Definitions}

Eligible patients were adults ( $>18$ years) diagnosed with $\mathrm{HCC}$ and treated with sorafenib. Patients receiving systemic therapy in combination with other treatments (eg, local ablative therapy/chemoembolization/SIRT) and patients with insufficient records were excluded from this study. Furthermore, we excluded patients with Child-Pugh score (CPS) class $\mathrm{C}$ and patients who died during ABT or within one week (7 days) after cessation of $\mathrm{ABT}$ in order to minimize the potential bias of infection-related mortality. Patient characteristics and information on antibiotic treatment (ABT), laboratory parameters (including AFP levels), tumor characteristics, and Eastern Cooperative Oncology Group performance status (ECOG PS) were collected from the clinical documentation system. ABT was defined as a prescription of any antibiotic substance within 30 days prior to or after the start of sorafenib. CPS was used to assess liver function at baseline. Baseline was defined as the date of sorafenib initiation.

\section{Statistics}

Statistical analyses were performed using IBM SPSS Statistics 26 (SPSS Inc., Armonk, New York, USA) R 4.1.1 ( $\mathrm{R}$ Core Team, R Foundation for Statistical Computing, Vienna, Austria) and GraphPad Prism 9 (GraphPad Software, La Jolla, California, USA). Continuous variables were reported as mean \pm standard deviation (SD) or median (interquartile range; IQR), and categorical variables were shown as numbers (n) and proportions (\%) of patients. Comparisons of proportions and of continuous variables were performed by Chi-squared test and unpaired Student's $t$-test, respectively. Overall survival (OS) was defined as the time from the start of sorafenib to the date of death or last contact. Progressionfree survival (PFS) was defined as the time from the start of sorafenib to the date of radiological progression or date of death/last follow-up, whatever came first. DCR was defined as the proportion of patients with complete response (CR), partial response (PR) or stable disease (SD) as the best objective response. Survival curves were calculated by Kaplan-Meier method and compared by Log rank test. Propensity score matching (1:5) was performed by applying the R "MatchIt" package. Restricted mean survival time (RMST) was calculated as an alternative 
measure of "life expectancy" until a given timepoint, if the "proportional hazards" assumption was not met. It is defined as the average time free from an event up to a milestone time point and thus a numeric expression of the area under the Kaplan-Meier survival curve. ${ }^{28,29}$ Restricted mean time lost (RMTL) was defined as the survival time lost up to a specific time point, thus representing the area above the Kaplan-Meier survival curve. ${ }^{30}$ R “survRM2" package was applied to RMST and RMTL calculations. Multivariable analyses were performed by Cox regression analysis and variables with a p-value $<0.1$ in univariable analysis and those considered relevant were included. A two-sided p-value $<0.05$ was considered to be statistically significant.

\section{Results}

\section{Patient Characteristics and Outcome}

In total, 346 patients with HCC were treated with sorafenib between 05/2006 and 03/2020 at the Division of Gastroenterology and Hepatology, Medical University of Vienna. Of those, patients were excluded from this study due to inadequate documentation $(n=49)$, combination treatment ( $\mathrm{n}=47)$, Child-Pugh class $\mathrm{C}(\mathrm{n}=42)$, and death within one week after ABT cessation $(n=2)$ (Figure 1). Consequently, 206 patients were included in this study. Detailed patient characteristics are shown in Table 1. The majority of patients were male $(n=171,83 \%)$ with a mean age of $66 \pm 9.6$ years. One-hundred forty-seven (71\%) patients had cirrhosis, predominantly with non-viral etiology $(n=147$; $71 \%)$. Almost half of the patients $(n=94,46 \%)$ had an impaired liver function, as defined by CPS B, and the majority of patients $(n=188,91 \%)$ had an intermediate-advanced stage HCC (BCLC B-C). Of note, baseline characteristics of patients who did $(n=23)$ and did not receive ABT $(n=183)$ were not significantly different (Table 1). Median time of follow-up was 10.8 (95\% CI: 9.2-12.3) months.

\section{Antibiotic Treatment}

Antibiotic treatment (ABT) was administered in 23 (11\%) patients for the following indications: hepatic encephalopathy $(n=6,26 \%)$, urinary tract infection $(n=5,22 \%)$, infection of unknown origin $(n=4,17 \%)$, and other infections requiring antimicrobial therapy $(n=8,35 \%)$ (Table 2). Penicillin $(n=13$, $57 \%$ ) was used most frequently, followed by rifaximin $(n=6$, $26 \%$ ), fluoroquinolones $(n=3,13 \%)$, and cephalosporins $(n=1$, $4 \%$ ). Overall, the median duration of antibiotic treatment was 14 (IQR: 12-30) days. In patients with rifaximin, the median duration of ABT was 127 (IQR: 30-528) days, while it was 14 (IQR: 9-14) days in patients receiving other antibiotic treatments. Antibiotics were prescribed within thirty days prior to and after sorafenib start in eleven (48\%) patients each, while one $(4 \%)$ patient was started on the day of sorafenib start.

\section{Antibiotic Treatment and Outcome}

Median OS was shorter in patients with ABT vs patients without ABT (4.7 (95\% CI: 3.2-6.1) months vs 11.4 (95\% CI: 9.9-12.9) months, $\mathrm{p}=0.012$ ) (Figure 2A, Table 3, Supplemental Table 1). In multivariable Cox regression analysis (Table 3), ABT (HR: 1.91 (95\% CI: 1.1-3.2), $\mathrm{p}=0.014)$ was significantly associated with

$n=346$ patients with HCC treated with sorafenib between 05/2006 and 03/2020

$\mathrm{n}=49$ excluded due to inadequate documentation

$\mathrm{n}=47$ excluded due to combination treatment

$\mathrm{n}=42$ excluded due to Child-Pugh class $C$

$n=2$ excluded due to death within one week after $A B T$ stop

$\mathrm{n}=206$ patients included in this study

Figure I Patient flow chart. 
Table I Patient Characteristics of Patients with and without Antibiotic Treatment

\begin{tabular}{|c|c|c|c|c|}
\hline & & $\begin{array}{l}\text { With ABT } \\
\quad(n=23)\end{array}$ & $\begin{array}{l}\text { Without ABT } \\
\quad(n=183)\end{array}$ & p-value \\
\hline & & \multicolumn{2}{|c|}{$\begin{array}{c}\text { Number (\%) or mean } \pm \mathrm{SD} / \text { median } \\
\text { (IQR) }\end{array}$} & \\
\hline Age (years) & $\begin{array}{l}\text { Mean } \pm S D \\
\text { Range }\end{array}$ & $\begin{array}{r}69 \pm 7 \\
56-82\end{array}$ & $\begin{array}{l}66 \pm 10 \\
28-88\end{array}$ & 0.080 \\
\hline Sex & $\begin{array}{l}\text { Male } \\
\text { Female }\end{array}$ & $\begin{array}{l}18(78 \%) \\
5(22 \%)\end{array}$ & $\begin{array}{l}153(84 \%) \\
30(16 \%)\end{array}$ & 0.556 \\
\hline Cirrhosis & $\begin{array}{l}\text { Yes } \\
\text { No }\end{array}$ & $\begin{array}{l}18(78 \%) \\
5(22 \%)\end{array}$ & $\begin{array}{l}129(71 \%) \\
54(29 \%)\end{array}$ & 0.437 \\
\hline Etiology & $\begin{array}{l}\text { Viral } \\
\text { Non-viral }\end{array}$ & $\begin{array}{l}8(35 \%) \\
15(65 \%)\end{array}$ & $\begin{array}{l}51(28 \%) \\
132(72 \%)\end{array}$ & 0.489 \\
\hline $\begin{array}{l}\text { Child-Pugh } \\
\text { Classification }\end{array}$ & $\begin{array}{l}\text { A } \\
\text { B }\end{array}$ & $\begin{array}{l}9(39 \%) \\
14(61 \%)\end{array}$ & $\begin{array}{l}103(56 \%) \\
80(44 \%)\end{array}$ & 0.120 \\
\hline ECOG PS & $\begin{array}{l}0 \\
\geq 1\end{array}$ & $\begin{array}{l}12(52 \%) \\
11(48 \%)\end{array}$ & $\begin{array}{l}114(62 \%) \\
69(38 \%)\end{array}$ & 0.348 \\
\hline $\begin{array}{l}\text { Macrovascular } \\
\text { invasion }\end{array}$ & $\begin{array}{l}\text { Yes } \\
\text { No }\end{array}$ & $\begin{array}{l}13(56 \%) \\
10(44 \%)\end{array}$ & $\begin{array}{l}82(45 \%) \\
101(55 \%)\end{array}$ & 0.375 \\
\hline $\begin{array}{l}\text { Extrahepatic } \\
\text { metastases }\end{array}$ & $\begin{array}{l}\text { Yes } \\
\text { No }\end{array}$ & $\begin{array}{l}9(39 \%) \\
14(61 \%)\end{array}$ & $\begin{array}{l}59(32 \%) \\
124(68 \%)\end{array}$ & 0.491 \\
\hline $\mathrm{BCLC}$ stage & $\begin{array}{l}A \\
B \\
C\end{array}$ & $\begin{array}{c}- \\
4(17 \%) \\
19(83 \%)\end{array}$ & $\begin{array}{l}18(10 \%) \\
41(22 \%) \\
124(68 \%)\end{array}$ & 0.207 \\
\hline AFP $(I U / m L)^{a}$ & $\begin{array}{l}<200 \\
\geq 200\end{array}$ & $\begin{array}{l}15(65 \%) \\
8(35 \%)\end{array}$ & $\begin{array}{l}92(59 \%) \\
63(41 \%)\end{array}$ & 0.592 \\
\hline CRP $(\mathrm{mg} / \mathrm{dL})^{\mathrm{b}}$ & $\begin{array}{l}<1 \\
1-5 \\
\geq 5\end{array}$ & $\begin{array}{l}6(26 \%) \\
9(39 \%) \\
8(35 \%)\end{array}$ & $\begin{array}{l}76(45 \%) \\
64(38 \%) \\
28(17 \%)\end{array}$ & 0.072 \\
\hline
\end{tabular}

Notes: ${ }^{a}$ Data available in $n=178$ patients. ${ }^{b}$ Data available in $n=191$ patients. Abbreviations: ABT, antibiotic treatment; AFP, $\alpha$-fetoprotein; BCLC, Barcelona Clinic Liver Cancer; CRP, C-reactive protein; ECOG PS, Eastern Cooperative Oncology Group performance status.

reduced OS, independently of performance status (HR: $1.61(95 \%$ CI: 1.1-2.3), $\mathrm{p}=0.009)$, AFP level (AFP $\geq$ 200IU/mL: HR: 1.56 (95\% CI: 1.1-2.2), $\mathrm{p}=0.012)$, CRP level (CRP 1-5 mg/dL: HR: 2.54 (95\% CI: 1.73.8), $\mathrm{p}<0.001$; CRP $\geq 5 \mathrm{mg} / \mathrm{dL}:$ HR: 1.97 (95\% CI: $1.2-$ 3.2), $\mathrm{p}=0.007$ ), etiology, CPS, and macrovascular invasion (all not significant). Within Child-Pugh stages, patients with ABT had a significantly shorter median OS compared to patients without ABT when classified as CPS A (3.5 (95\% CI: 0-7.6) vs 14.3 (95\% CI: $10.8-$ 17.9) months, $\mathrm{p}=0.003$ ), while only a trend was observed in CPS B (4.7 (95\% CI: $1.0-8.4)$ vs 8.2 (95\% CI: $6.2-$ 10.2) months, $\mathrm{p}=0.598$ ). There was also a trend towards shorter PFS in the ABT group (3.5 (95\% CI: 1.6-5.4) months vs 4.8 (95\% CI: 3.9-5.7) months, $\mathrm{p}=0.099)$ (Figure 2B), which remained statistically nonsignificant in multivariable analysis (Supplemental Table 2).

\section{Evaluation of Best Overall Response}

One hundred fifty-two patients (74\%) had at least one followup imaging and were therefore evaluable for the best radiological response assessment. In the non-ABT $(n=136)$ vs ABT group $(\mathrm{n}=16), 10(7 \%)$ vs $0(0 \%)$ had complete/partial response, $48(35 \%)$ vs $7(44 \%)$ had stable disease, and 78 $(58 \%)$ vs $9(56 \%)$ had progressive disease. Even though there was no difference in disease-control rate (ABT vs non-ABT group, $44 \%$ vs $43 \%$ ), none of the patients who received antibiotics had a complete or partial response.

\section{ABT and Outcome (Propensity Score Matched Cohort)}

In order to balance prognostic factors between patients with and without ABT, propensity score matching (1:5) using CPS, macrovascular invasion, extrahepatic spread, and ECOG performance status was performed. The propensity score matched cohort included 138 patients, of whom 23 patients belonged to the ABT group and 115 to the non-ABT group. Baseline characteristics were well balanced between the two groups (Supplemental Table 3). There was a clear trend towards shorter OS (4.7 (95\% CI: 3.2-6.1) vs 11.3 (95\% CI: 9.1-13.4) months, $\mathrm{p}=0.079$ ) in patients with $\mathrm{ABT}$ vs without ABT (Supplemental Figure 1).

Since there was an obvious difference in median OS within the first 12 months, we calculated RMTL up to this timepoint. Patients in the ABT group had a RMTL of 6.2 (95\% CI: 4.6-7.8) months, compared to 3.5 (95\% CI: 2.7-4.3) months in patients without ABT, resulting in a difference of -2.7 (95\% CI: $-4.5-[-0.9], \mathrm{p}=0.003)$ months lost. Similar results were obtained when investigating the RMTL between patients with and without ABT within the first 24 months (16.2 (95\% CI: 12.919.4) vs 11.7 (95\% CI: 10.2-13.3) months), resulting in a difference of -4.4 (95\% CI: $-8.0-[-0.9]), \mathrm{p}=0.015)$ months lost.

\section{Discussion}

While evidence on the impact of ABT on immunotherapy efficacy is increasing, studies evaluating the association between ABT and outcome of cancer patients treated with 
Table 2 Antibiotic Treatment 30 Days Prior to or After Sorafenib Initiation

\begin{tabular}{|c|c|c|}
\hline & & Number (\%) or Mean \pm SD/Median (Range) \\
\hline Number of patients with antibiotic treatment & & $23(100 \%)$ \\
\hline \multirow[t]{4}{*}{ Type of antibiotic treatment } & Penicillin & $13(54 \%)$ \\
\hline & Rifaximin & $6(25 \%)$ \\
\hline & Fluoroquinolone & $4(17 \%)$ \\
\hline & Cephalosporin & I (4\%) \\
\hline \multirow[t]{4}{*}{ Indication for antibiotic treatment } & $\mathrm{HE}$ & $7(30 \%)$ \\
\hline & UTI & $5(22 \%)$ \\
\hline & Infection of unknown origin & $4(18 \%)$ \\
\hline & Other & $7(30 \%)$ \\
\hline Median duration of antibiotic treatment (days) & Median (IQR) & $14(12-30)$ \\
\hline \multirow[t]{3}{*}{ Initiation of antibiotic treatment } & Prior to sorafenib start & II (48\%) \\
\hline & After sorafenib start & II (48\%) \\
\hline & At sorafenib start & I (4\%) \\
\hline
\end{tabular}

Abbreviations: HE, hepatic encephalopathy; UTI, urinary tract infection.

TKIs are lacking. In our cohort of 206 patients with HCC treated with sorafenib, antibiotic treatment (30 days prior to or after sorafenib initiation) was independently associated with worse OS. Additionally, none of the patients in the ABT group had a complete or partial response to sorafenib treatment.

Mechanistically, the negative association between ABT and survival may be related to ABT-induced disruption of the gut microbiome. The gut microbiome acts as a key modulator of the immune system by regulating local as well as systemic immunity and by exerting tumorpromoting and tumor-suppressing functions. ${ }^{14}$ While some patients are responders to certain anti-cancer therapies, some do not derive any clinical benefit from the same treatments. Besides other patient and tumor factors, this may also be partly related to differences in the composition of the gut microbiome. Preclinical studies highlighted the importance of the gut microbiome in the context of controlling anti-tumor responses to chemotherapy ${ }^{31,32}$ and immunotherapy. ${ }^{33,34}$

Recent clinical evidence suggests differences in the diversity and composition of the gut microbiome in patients who respond and do not respond to immunotherapy, ${ }^{19,20}$ including $\mathrm{HCC}$ patients. ${ }^{35}$ Hence, modulation of the gut microbiome emerges as a promising target to improve efficacy of cancer treatment.

Experimental exposition of germ-free mice with fecal material from patients responding to immunotherapy led to improved tumor control, augmented immune responses, and greater efficacy of antitumor therapy. ${ }^{19,20}$ In line with this, fecal microbiota transplantation improved the response to reinitiated PD-1-targeted ICIs in immunotherapy-refractory melanoma patients. ${ }^{21,22}$ Data suggesting that the gut microbiome affects the outcome of patients with HCC treated with immunotherapy were reported recently. ${ }^{35}$

ABT imposes profound changes on the diversity of the gut microbial system ${ }^{36}$ which, in combination with anti-cancer therapies, might impact the outcome of cancer patients. Indeed, recent evidence supports a negative association between $\mathrm{ABT}$ and clinical outcomes in cancer patients treated with TKIs, ${ }^{17,24}$ chemotherapy ${ }^{31}$ and ICI therapy. ${ }^{13,19,20,23,35}$ While concomitant therapy with antibiotics and epidermal growth factor receptor (EGFR)-TKIs in patients with advanced non-small cell lung cancer (NSCLC) was associated with shorter PFS, there were no changes in ORR or DCR in another study. ${ }^{24}$ In patients with metastatic renal cell carcinoma (mRCC) treated with VEGF-targeting therapies among others, antibiotic users had a shorter PFS and lower ORR compared to antibiotic nonusers, while OS was not negatively impacted by $\mathrm{ABT}$ in the group of patients receiving antiVEGF therapy. ${ }^{17}$ Furthermore, initiation and duration of $\mathrm{ABT}$ seems to be relevant in this context. Pinato et al reported a time-dependence of antibiotics exposure as a strong determinant of outcome in patients treated with ICIs, as those with initiation of antibiotics prior to ICI therapy had an increased risk of primary progression compared to patients with concurrent $\mathrm{ABT}^{37}$ Others suggested that the duration of $\mathrm{ABT}$ may 


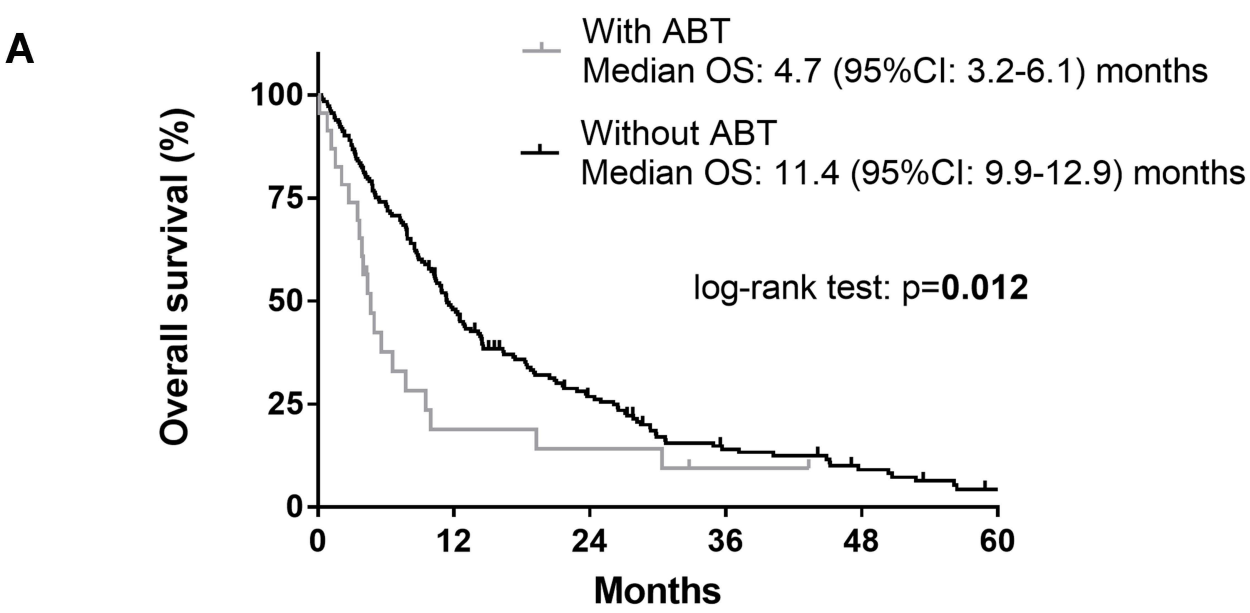

No. at risk:

With ABT

Without ABT

23

5

4
41

2

19

$\begin{array}{cc}0 & 0 \\ 11 & 4\end{array}$

B

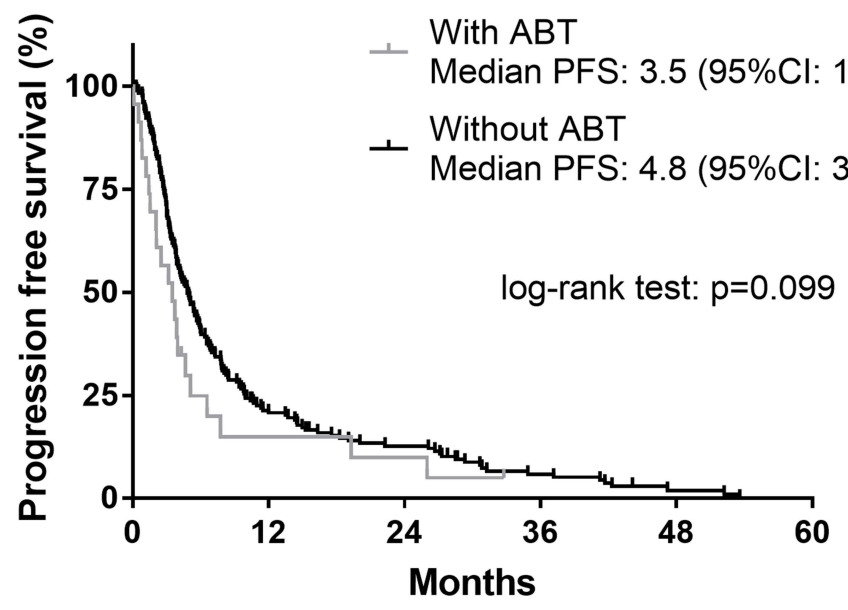

No. at risk:

With ABT

Without $A B T$

$\begin{array}{ccc}23 & 4 & 3 \\ 183 & 36 & 21\end{array}$

$\begin{array}{lll}0 & 0 & 0 \\ 9 & 3 & 1\end{array}$

Figure 2 Survival curves of patients with and without antibiotic treatment 30 days prior to or after sorafenib initiation. (A) Overall survival and (B) progression-free survival. Kaplan-Meier survival curves of patients with and without ABT were compared by Log rank test.

negatively impact the outcome of patients receiving immunotherapy rather than the use of antibiotics per se. ${ }^{38}$

Recently, the combination of atezolizumab plus bevacizumab has become the new systemic front-line treatment for patients with HCC. ${ }^{7-9}$ Since most patients with HCC have an underlying liver cirrhosis, a condition typically associated with intestinal dysbiosis, ${ }^{39}$ this patient group may particularly benefit from microbiome modulation in order to prevent immunotherapy failure. In addition, the impaired gastrointestinal barrier and systemic inflammation in cirrhosis are also impacted by portal hypertension and beta blocker therapy. ${ }^{26,40}$ However, sorafenib itself may influence portal pressure ${ }^{41}$ and thus, modulate 
Table 3 Uni- and Multivariable Cox Regression Analysis of Prognostic Factors for Overall Survival

\begin{tabular}{|c|c|c|c|c|c|c|c|}
\hline & & \multicolumn{3}{|c|}{ Univariable } & \multicolumn{3}{|c|}{ Multivariable } \\
\hline & & HR & $95 \% \mathrm{Cl}$ & p-value & HR & $95 \% \mathrm{Cl}$ & p-value \\
\hline Antibiotic treatment & $\begin{array}{l}\text { No } \\
\text { Yes }\end{array}$ & $\begin{array}{c}1 \\
1.81\end{array}$ & $1.13-2.89$ & $0.014^{*}$ & $\begin{array}{c}1 \\
1.91\end{array}$ & $|| 4-3.21$. & $0.014 *$ \\
\hline Etiology & $\begin{array}{c}\text { Viral } \\
\text { Non-viral }\end{array}$ & $\begin{array}{c}1 \\
1.39\end{array}$ & $0.99-1.94$ & 0.059 & $\begin{array}{c}1 \\
1.19\end{array}$ & $0.80-1.76$ & 0.388 \\
\hline Child-Pugh Classification & $\begin{array}{l}A \\
B\end{array}$ & $\begin{array}{c}1 \\
1.59\end{array}$ & $1.18-2.13$ & 0.002 & $\begin{array}{c}1 \\
1.22\end{array}$ & $0.87-|.7|$ & 0.256 \\
\hline ECOG PS & $\begin{array}{c}0 \\
\geq 1\end{array}$ & $\begin{array}{c}1 \\
2.04\end{array}$ & $1.50-2.77$ & $<0.00 \mathrm{I}$ & $\begin{array}{c}1 \\
1.61\end{array}$ & I.13-2.29 & 0.009 \\
\hline Macrovascular invasion & $\begin{array}{l}\text { No } \\
\text { Yes }\end{array}$ & $\begin{array}{c}1 \\
1.43\end{array}$ & $1.06-1.92$ & 0.020 & $\begin{array}{c}1 \\
1.13\end{array}$ & $0.8 \mathrm{I}-1.60$ & 0.471 \\
\hline Extrahepatic spread & $\begin{array}{l}\text { No } \\
\text { Yes }\end{array}$ & $\begin{array}{c}1 \\
1.08\end{array}$ & $0.79-1.49$ & 0.620 & - & - & - \\
\hline AFP $(I U / m L)$ & $\begin{array}{l}<200 \\
\geq 200\end{array}$ & $\begin{array}{c}1 \\
1.68\end{array}$ & $1.21-2.32$ & 0.002 & $\begin{array}{c}1 \\
1.56\end{array}$ & I.10-2.20 & 0.012 \\
\hline CRP (mg/dL) & $\begin{array}{l}<I \\
I-5 \\
\geq 5\end{array}$ & $\begin{array}{c}1 \\
2.93 . \\
3.06\end{array}$ & $\begin{array}{l}2.05-4.30 \\
1.99-4.69\end{array}$ & $\begin{array}{l}<0.001 \\
<0.001\end{array}$ & $\begin{array}{c}1 \\
2.54 \\
1.97\end{array}$ & $\begin{array}{l}\text { I.70-3.77 } \\
\text { I.20-3.24 }\end{array}$ & $\begin{array}{c}<0.001 \\
0.007\end{array}$ \\
\hline
\end{tabular}

Note: *Significant values were marked bold.

Abbreviations: AFP, $\alpha$-fetoprotein; CRP, C-reactive protein; ECOG PS, Eastern Cooperative Oncology Group performance status.

the mucosal barrier and molecular signaling through the gut-liver axis. ${ }^{25}$

We acknowledge some limitations of this study. Due to the retrospective design, some information on patient characteristics might not have been documented in full detail. Furthermore, even though our observations are consistent with previously reported data about possible negative effects of antibiotics, use of antibiotics might identify patients with poorer prognosis due to the indication for antibiotic treatment at treatment initiation (ie, bacterial infection in the majority of patients) or an increased susceptibility for infections during follow-up, which increase mortality in patients with cirrhosis. ${ }^{42}$ In order to correct for this potential bias, we excluded patients who died within 7 days after cessation of ABT (even though this may not fully reflect the increased risk of infection-related mortality) and CPS C patients, who are particularly prone to infections. Moreover, we can only speculate about a link between $\mathrm{ABT}$ and gut microbiome, as we were not able to analyze microbial composition in this retrospective study.
In conclusion, $\mathrm{ABT}$ was associated with worse $\mathrm{OS}$ in patients with advanced HCC treated with sorafenib. Moreover, there was a trend towards shorter PFS, and none of the patients in the $\mathrm{ABT}$ group had a complete or partial response. Changes in the composition of the gut microbiome due to ABT may affect the response to systemic anticancer therapies, including TKIs. Future prospective studies are needed to validate ABT-mediated changes in the gut microbiome as a potential mechanism for failure of TKI therapy.

\section{List of Abbreviations}

ABT, antibiotic treatment; AFP, $\alpha$-fetoprotein; BCLC, Barcelona clinic liver cancer; CI, confidence interval; CPS, Child-Pugh score; CRP, C-reactive protein; CT, computed tomography; ECOG-PS, Eastern Cooperative Oncology Group performance status; HBV, hepatitis B virus; HCC, hepatocellular carcinoma; HCV, hepatitis $\mathrm{C}$ virus; ICI, immune checkpoint inhibitor; MRI, magnetic resonance imaging; MWA, microwave ablation; OS, overall survival; RFA, radiofrequency ablation; TACE, transarterial chemoembolization; TKI, tyrosine kinase inhibitor. 


\section{Author Contributions}

All authors contributed to data collection or analysis, drafting or revising the article, gave final approval for the version to be published, agreed to the submitted journal, and agreed to be accountable for all aspects of the work.

\section{Funding}

There is no funding to report.

\section{Disclosure}

Dr. Katharina Pomej and Dr. Lorenz Balcar are co-first authors of this study. Dr. Bernhard Scheiner received travel support from Gilead, Ipsen and AbbVie. Dr. Mattias Mandorfer served as a speaker and/or consultant and/or advisory board member for AbbVie, Bristol-Myers Squibb, Collective Acumen, Gilead, and W. L. Gore \& Associates and received travel support from AbbVie, Bristol-Myers Squibb, and Gilead. Dr. Thomas Reiberger received travel support from Gilead, Roche, MSD, and Gore; grant support from Gilead, AbbVie, Philips, Boehringer Ingelheim, Phenex Pharmaceuticals, and Gore, and served as a consultant for MSD, Gilead, AbbVie, Intercept, Siemens, and Boehringer Ingelheim. Prof. Dr. Michael Trauner received grant support from Albireo, Alnylam, Cymabay, Falk, Gilead, Intercept, MSD, Takeda, and UltraGenyx, honoraria for consulting from BiomX, Boehringer Ingelheim, Falk, Genfit, Gilead, Intercept, Janssen, MSD, Novartis, Phenex, Regulus and Shire, speaker fees from BMS, Falk, Gilead, Intercept and MSD, as well as travel support from AbbVie, Falk, Gilead, Intercept, and Roche. Prof. Dr. Michael Trauner is also coinventor of patents on the medical use of 24-norursodeoxycholic acid. Dr. Matthias Pinter is an investigator for Bayer, BMS, Lilly, and Roche; he received speaker honoraria from Bayer, BMS, Eisai, Lilly, and MSD; he is a consultant for Bayer, BMS, Ipsen, Eisai, Lilly, MSD, and Roche; he received travel support from Bayer and BMS. The authors report no other conflicts of interest in this work.

\section{References}

1. Torre LA, Bray F, Siegel RL, Ferlay J, Lortet-Tieulent J, Jemal A. Global cancer statistics, 2012. CA Cancer J Clin. 2015;65(2):87-108. doi:10.3322/caac. 21262

2. EASL Clinical Practice Guidelines. Management of hepatocellular carcinoma. $J$ Hepatol. 2018;69(1):182-236. doi:10.1016/j. jhep.2018.03.019
3. Blachier M, Leleu H, Peck-Radosavljevic M, Valla DC, RoudotThoraval F. The burden of liver disease in Europe: a review of available epidemiological data. $J$ Hepatol. 2013;58(3):593-608. doi:10.1016/j.jhep.2012.12.005

4. Pinter M, Trauner M, Peck-Radosavljevic M, Sieghart W. Cancer and liver cirrhosis: implications on prognosis and management. ESMO Open. 2016;1(2):e000042. doi:10.1136/esmoopen-2016-000042

5. Pinter M, Peck-Radosavljevic M. Review article: systemic treatment of hepatocellular carcinoma. Aliment Pharmacol Ther. 2018;48 (6):598-609. doi:10.1111/apt.14913

6. Scheiner B, Kirstein M, Popp S, et al. Association of platelet count and mean platelet volume with overall survival in patients with cirrhosis and unresectable hepatocellular carcinoma. Liver Cancer. 2019;8(3):203-217. doi:10.1159/000489833

7. Finn RS, Qin S, Ikeda M, et al. Atezolizumab plus bevacizumab in unresectable hepatocellular carcinoma. $N$ Engl J Med. 2020;382 (20):1894-1905. doi:10.1056/NEJMoa1915745

8. Pinter M, Jain RK, Duda DG. The current landscape of immune checkpoint blockade in hepatocellular carcinoma: a review. JAMA oncol. 2021;7(1):113-123. doi:10.1001/jamaoncol.2020.3381

9. Pinter M, Scheiner B, Peck-Radosavljevic M. Immunotherapy for advanced hepatocellular carcinoma: a focus on special subgroups. Gut. 2021;70(1):204-214. doi:10.1136/gutjnl-2020-321702

10. Bruix J, Qin S, Merle P, et al. Regorafenib for patients with hepatocellular carcinoma who progressed on sorafenib treatment (RESORCE): a randomised, double-blind, placebo-controlled, Phase 3 trial. Lancet. 2017;389(10064):56-66. doi:10.1016/s0140-6736(16) 32453-9

11. Kudo M. Targeted and immune therapies for hepatocellular carcinoma: predictions for 2019 and beyond. World $j$ Gastroenterol. 2019;25(7):789-807. doi:10.3748/wjg.v25.i7.789

12. Abou-Alfa GK, Meyer T, Cheng AL, et al. Cabozantinib in patients with advanced and progressing hepatocellular carcinoma. $N$ Engl $J$ Med. 2018;379(1):54-63. doi:10.1056/NEJMoa1717002

13. Pinato DJ, Gramenitskaya D, Altmann DM, et al. Antibiotic therapy and outcome from immune-checkpoint inhibitors. $J$ Immunother Cancer. 2019;7(1):287. doi:10.1186/s40425-019-0775-x

14. Schwabe RF, Greten TF. Gut microbiome in HCC - mechanisms, diagnosis and therapy. $J$ Hepatol. 2020;72(2):230-238. doi:10.1016/j. jhep.2019.08.016

15. Zitvogel L, Ma Y, Raoult D, Kroemer G, Gajewski TF. The microbiome in cancer immunotherapy: diagnostic tools and therapeutic strategies. Science. 2018;359(6382):1366-1370. doi:10.1126/ science.aar6918

16. Routy B, Le Chatelier E, Derosa L, et al. Gut microbiome influences efficacy of PD-1-based immunotherapy against epithelial tumors. Science. 2018;359(6371):91-97. doi:10.1126/science.an3706

17. Lalani AA, Xie W, Braun DA, et al. Effect of antibiotic use on outcomes with systemic therapies in metastatic renal cell carcinoma. Eur Urol Oncol. 2020;3(3):372-381. doi:10.1016/j. euo.2019.09.001

18. Hopkins AM, Kichenadasse G, Karapetis CS, Rowland A, Sorich MJ. Concomitant antibiotic use and survival in urothelial carcinoma treated with atezolizumab. Eur Urol. 2020;78(4):540-543. doi:10.1016/j. eururo.2020.06.061

19. Gopalakrishnan V, Spencer CN, Nezi L, et al. Gut microbiome modulates response to anti-PD-1 immunotherapy in melanoma patients. Science. 2018;359(6371):97-103. doi:10.1126/science. aan4236

20. Matson V, Fessler J, Bao R, et al. The commensal microbiome is associated with anti-PD-1 efficacy in metastatic melanoma patients. Science. 2018;359(6371):104-108. doi:10.1126/science.aao3290

21. Davar D, Dzutsev AK, McCulloch JA, et al. Fecal microbiota transplant overcomes resistance to anti-PD-1 therapy in melanoma patients. Science. 2021;371(6529):595-602. doi:10.1126/science. abf3363 
22. Baruch EN, Youngster I, Ben-Betzalel G, et al. Fecal microbiota transplant promotes response in immunotherapy-refractory melanoma patients. Science. 2021;371(6529):602-609. doi:10.1126/science.abb5920

23. Alshammari K, Alsugheir F, Aldawoud M, et al. Association between antibiotic exposure and survival in patients with hepatocellular carcinoma treated with nivolumab. J Clin Oncol. 2021;39(15_suppl): e16186-e16186. doi:10.1200/JCO.2021.39.15_suppl.e16186

24. Liu K, Zhang W, Tan Q, Jiang G, Jia J. Antibiotic use is a negative predictor of the efficacy and toxicity of epidermal growth factor receptor-targeted therapy in advanced non-small cell lung cancer. Oncol Lett. 2019;18(3):2677-2683. doi:10.3892/ol.2019.10481

25. Simbrunner B, Mandorfer M, Trauner M, Reiberger T. Gut-liver axis signaling in portal hypertension. World J Gastroenterol. 2019;25 (39):5897-5917. doi:10.3748/wjg.v25.i39.5897

26. Reiberger T, Ferlitsch A, Payer BA, et al. Non-selective betablocker therapy decreases intestinal permeability and serum levels of LBP and IL-6 in patients with cirrhosis. J Hepatol. 2013;58(5):911-921. doi:10.1016/j.jhep.2012.12.011

27. Behary J, Amorim N, Jiang XT, et al. Gut microbiota impact on the peripheral immune response in non-alcoholic fatty liver disease related hepatocellular carcinoma. Nat Commun. 2021;12(1):187. doi:10.1038/s41467-020-20422-7

28. Royston P, Parmar MKB. Restricted mean survival time: an alternative to the hazard ratio for the design and analysis of randomized trials with a time-to-event outcome. BMC Med Res Methodol. 2013;13(1):152. doi:10.1186/1471-2288-13-152

29. Huang B, Kuan PF. Comparison of the restricted mean survival time with the hazard ratio in superiority trials with a time-to-event end point. Pharm Stat. 2018;17(3):202-213. doi:10.1002/pst.1846

30. Uno H, Claggett B, Tian L, et al. Adding a new analytical procedure with clinical interpretation in the tool box of survival analysis. Ann Oncol. 2018;29(5):1092-1094. doi:10.1093/annonc/mdy109

31. Viaud S, Saccheri F, Mignot G, et al. The intestinal microbiota modulates the anticancer immune effects of cyclophosphamide. Science. 2013;342(6161):971-976. doi:10.1126/science.1240537

32. Iida N, Dzutsev A, Stewart CA, et al. Commensal bacteria control cancer response to therapy by modulating the tumor microenvironment. Science. 2013;342(6161):967-970. doi:10.1126/ science. 1240527
33. Sivan A, Corrales L, Hubert N, et al. Commensal Bifidobacterium promotes antitumor immunity and facilitates anti-PD-L1 efficacy. Science. 2015;350(6264):1084-1089. doi:10.1126/science.aac4255

34. Vétizou M, Pitt JM, Daillère R, et al. Anticancer immunotherapy by CTLA-4 blockade relies on the gut microbiota. Science. 2015;350 (6264):1079-1084. doi:10.1126/science.aad1329

35. Zheng Y, Wang $T$, Tu X, et al. Gut microbiome affects the response to anti-PD-1 immunotherapy in patients with hepatocellular carcinoma. J Immunother Cancer. 2019;7(1):193. doi:10.1186/s40425-019-0650-9

36. Francino MP. Antibiotics and the human gut microbiome: dysbioses and accumulation of resistances. Front Microbiol. 2015;6:1543. doi:10.3389/fmicb.2015.01543

37. Pinato DJ, Howlett S, Ottaviani D, et al. Association of prior antibiotic treatment with survival and response to immune checkpoint inhibitor therapy in patients with cancer. JAMA oncol. 2019;5 (12):1774-1778. doi:10.1001/jamaoncol.2019.2785

38. Galli G, Triulzi T, Proto C, et al. Association between antibiotic-immunotherapy exposure ratio and outcome in metastatic non small cell lung cancer. Lung Cancer. 2019;132:72-78. doi:10.1016/j.lungcan.2019.04.008

39. Tripathi A, Debelius J, Brenner DA, et al. The gut-liver axis and the intersection with the microbiome. Nat Rev Gastroenterol Hepatol. 2018;15(7):397-411. doi:10.1038/s41575-018-0011-z

40. Jachs M, Hartl L, Schaufler D, et al. Amelioration of systemic inflammation in advanced chronic liver disease upon beta-blocker therapy translates into improved clinical outcomes. Gut. 2020. doi:10.1136/gutjnl-2020-322712

41. Pinter M, Sieghart W, Reiberger T, Rohr-Udilova N, Ferlitsch A, Peck-Radosavljevic M. The effects of sorafenib on the portal hypertensive syndrome in patients with liver cirrhosis and hepatocellular carcinoma-a pilot study. Aliment Pharmacol Ther. 2012;35(1):83-91. doi:10.1111/j.1365-2036.2011.04896.x

42. Piano S, Brocca A, Mareso S, Angeli P. Infections complicating cirrhosis. Liver Int. 2018;38(Suppl 1):126-133. doi:10.1111/liv.13645
Journal of Hepatocellular Carcinoma

\section{Publish your work in this journal}

The Journal of Hepatocellular Carcinoma is an international, peerreviewed, open access journal that offers a platform for the dissemination and study of clinical, translational and basic research findings in this rapidly developing field. Development in areas including, but not limited to, epidemiology, vaccination, hepatitis therapy, pathology and molecular tumor classification and prognostication are all considered for publication. The manuscript management system is completely online and includes a very quick and fair peer-review system, which is all easy to use. Visit http://www.dovepress.com/ testimonials.php to read real quotes from published authors. 